\title{
CIUDAD, POBREZA, TUGURIO. Aportes de los pobres a la construcción del hábitat popular
}

Joan Mac Donald *

\section{Resumen}

Este texto desarrolla en diez temas las prácticas identificadas en el trabajo con comunidades pobres en tugurios de África, Asia y América Latina. Se invita en él a reflexionar sobre el potencial que tienen los pobres para aportar a la construcción de mejores ciudades en nuestros países y a renovar algunas premisas que han fundamentado las políticas convencionales en relación con la pobreza urbana y la precariedad del alojamiento.

Entre otras cuestiones, nos preguntamos qué significa para estas comunidades ubicarse en las ciudades y se comparan los conceptos que subyacen a nuestra manera de entender la pobreza, la precariedad y la segregación urbanas con aquellos que están detrás de las formas en que los pobres localizan y construyen su hábitat. Finalmente se identifican algunos recursos estratégicos que los movimientos populares están aprendiendo a usar para fortalecer los procesos de mejoramiento del hábitat precario, la articulación de intereses, las ventajas de una información oportuna y el desarrollo de capacidades en materia financiera y tecnológica.

\section{Palabras clave}

Pobreza; Mejoramiento urbano; Slums; Movimientos populares

\section{Abstract: CITY, POVERTY, HUT. Contributions of the poor to the construction of popular housing}

This paper develops in ten sections the practices identified after working with poor communities in slums in Africa, Asia and Latin America. It invites the reader to consider the potential of poor communities to contribute to building better cities in our countries and renew some of the premises of conventional policies on urban poverty and precarious housing. It starts by asking what it means for poor communities to be located in cities. Also, it compares the underlying concepts of the way we understand urban poverty, precariousness and segregation with those that explain the ways poor communities locate and build their habitat. Finally, it identifies some strategic resources that popular movements are learning to use to strengthen the processes of improving precarious housing, such as working at a large scale, considering various interests, using timely information and developing financial and technological skills.

\section{Key words}

Poverty, Urban Improvement, Slums, Popular Movements

\footnotetext{
Recibido: 11/09/2011; aceptado definitivamente: 16/07/2012
}

\footnotetext{
* Arquitecta, presidenta de SELAVIP: Hogar de Cristo 3812 Casilla 112-2. Santiago de Chile. selavip@vtr.net
} 


\section{Introducción}

Aliviar la pobreza y la precariedad del hábitat en las ciudades es uno de los desafíos más importantes que encaran las políticas urbanas de los países en desarrollo. Desde diversos ámbitos se organizan foros para compartir estudios sobre las dimensiones, características y raíces de la crítica situación de miles de millones de personas marginadas de las oportunidades que ofrecen los centros urbanos a los demás habitantes. A su vez, organismos multinacionales, entidades de cooperación al desarrollo, gobiernos, municipios y equipos profesionales desarrollan múltiples propuestas para encarar esta situación y exploran de manera permanente nuevos caminos para aumentar su eficacia y eficiencia. Todas estas iniciativas han llegado a constituir un valioso bagaje de información que está disponible para apoyar la construcción de ciudades más equitativas en el mundo en desarrollo.

Sin embargo, se conocen escasamente los avances logrados por los propios afectados -los pobres urbanos y los habitantes de tugurios-en sus incansables esfuerzos por mejorar viviendas $y$ barrios combinando sus exiguos recursos con las escasas oportunidades que les ofrece la ciudad moderna. A veces se trata de vivencias y aprendizajes aislados; en otros casos, de experiencias más estructuradas 0 prácticas compartidas que en su conjunto sugieren la revisión de afirmaciones hasta ahora indiscutidas y dan cuenta de una gama de destrezas y recursos que es posible incorporar en los programas de mejoramiento del hábitat popular.

Este texto desarrolla en diez temas el tipo de prácticas identificadas, que surgen del trabajo con comunidades pobres en tugurios de África, Asia y
América Latina ${ }^{1}$. Estos temas invitan a reflexionar sobre el potencial que tienen los pobres para aportar a la construcción de mejores ciudades en nuestros países y a renovar algunas premisas que han fundamentado las políticas convencionales en relación con la pobreza urbana y la precariedad del alojamiento.

\section{¿Hacen bien los pobres al concentrarse en ciudades?}

La acelerada urbanización que sucede en el mundo en desarrollo ha llevado a un aumento explosivo de la población en ciudades ${ }^{2}$. Gran parte de esta población urbana es pobre y/o vive en asentamientos precarios. Ante la percepción generalizada de que la pobreza se acentúa porque la población pobre abandona las áreas rurales para instalarse en ciudades donde sería aún más difícil sobrevivir, muchas políticas de ordenamiento territorial intentan retenerla en el campo aplicando programas de desarrollo rural. Sin desconocer la importancia de estos programas, se debe aceptar que ellos han tenido escaso efecto para frenar la urbanización en el mundo en desarrollo. Sobre todo los pobres continúan migrando a las áreas urbanas, y dentro de ellas, a los centros de mayor tamaño. No parece asustarlos la imagen de ciudades en que predomina ampliamente la pobreza y la precariedad, y tampoco aceptan la

\footnotetext{
1 SELAVIP es la Secretaría de América Latina, Caribe, África y Asia para la Vivienda Popular. Como fundación privada, desde hace casi cuarenta años apoya proyectos de vivienda para familias muy pobres en las ciudades de América Latina, Asia y África. Aborda sobre todo la extrema emergencia social promoviendo la construcción de viviendas modestas que permitan a los más pobres solucionar el problema del techo con la urgencia requerida. Su Directorio se reúne anualmente en Bruselas, Bélgica para aprobar las directrices de funcionamiento de su entidad operativa ubicada en Santiago de Chile. Durante los años 2007 y 2008 SELAVIP ha operado unos 120 proyectos en 12 países de América Latina y el Caribe, 13 países de África y 10 países de Asia. Para más información, consultar la web de SELAVIP:<www.selavip.org>

2 La población urbana aumentó de 1.500 millones de personas en 1990 a unos 2.300 millones en 2005 y se acercará a los 3.000 millones en el año 2015. En América Latina la población urbana se empinaba ya en los años 1960 por sobre el $50 \%$ de población urbana, y hoy 8 de cada 10 habitantes vive en áreas urbanas. En los otros dos continentes la población urbana igualará a la rural en la próxima década y aumentará su presencia en las siguientes.
} 
idea de que en ellas la lucha por superar la pobreza sería más dura que en el campo. Por el contrario, acuden a las ciudades justamente para salir de la pobreza. Y las cifras avalan la validez de su decisión. En casi todos los países la pro- porción de hogares pobres es mayor en sectores rurales que en las áreas urbanas y es menos probable ser pobre y habitar de manera precaria en las grandes ciudades que en los centros de menor tamaño.

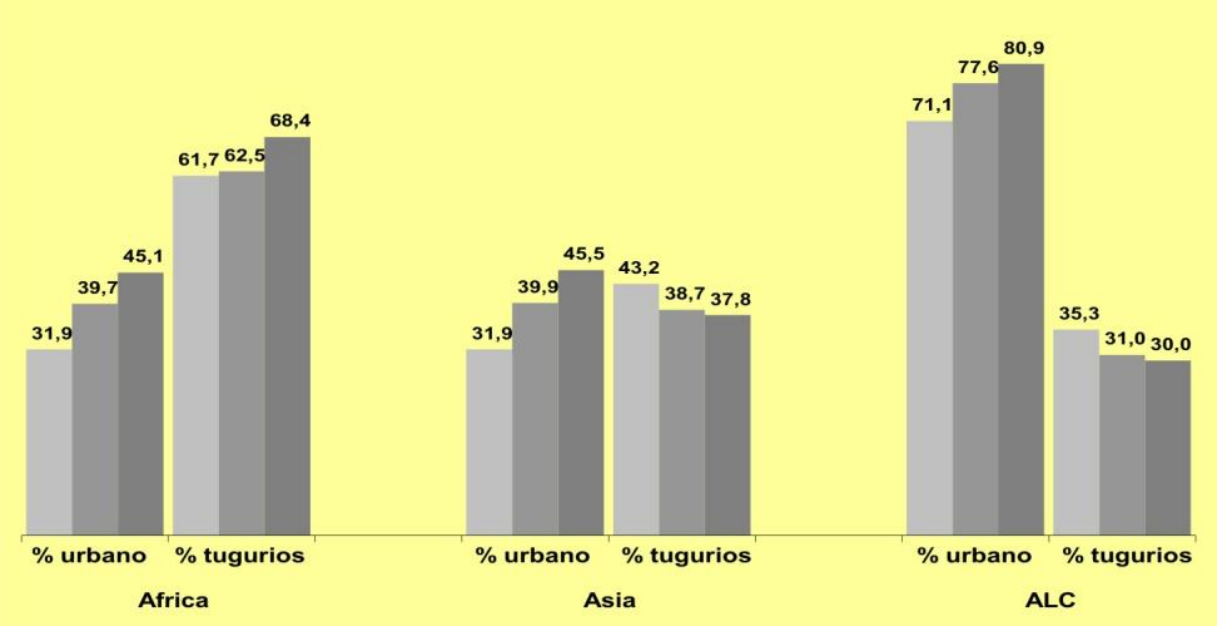

Figura 1. Urbanización y tugurios (\% de población urbana).

La urbanización también ha tenido efectos positivos en la evolución de la precariedad del hábitat. En América Latina y Asia, a medida que los países llegan a ser más urbanos disminuye la proporción de población en tugurios y la pobreza. La llamada "urbanización de la pobreza" que da cuenta de un aumento de la pobreza en las ciudades no significa entonces -al menos en estas dos regiones- que haya más pobreza a causa del crecimiento de las ciudades, sino que ella ahora se concentra en los centros urbanos. La acumulación de carencias en estos espacios urbanos implica por cierto nuevos problemas frente a un cuadro de pobreza rural dispersa, pero también ofrece ventajas ya que es posible proveer bienes y servicios urbanos en escala masiva y a menores costos. Además confiere a los más pobres una presencia política y un potencial de organización que facilita la lucha por el progreso.

\section{¿Absorción o articulación compensada?}

Sin acceso a los suelos de cierta calidad urbana, los pobres se han visto históricamente confinados a la periferia de las ciudades o a algunos terrenos residuales en el interior de las mismas que no resultan atractivos para los sectores de mayor ingreso, ya sea porque implican riesgo ante desastres naturales o porque están cercanos a focos de insalubridad como basurales o desagües cloacales. Esto se ha expresado a nivel de las ciudades en la coexistencia de dos tipos de espacios claramente diferenciados: los que corresponden a la ciudad formal, ocupados por los sectores de más recursos, y aquellos que conforman la ciudad informal, en que habitan los pobres. Si bien este patrón ha evolucionado en décadas recientes hacia una compleja fragmentación del tejido urbano en que ciudadanos "de primera" y "de segunda" están físicamente más cercanos, las distancias sociales entre ellos son ahora aún más acentuadas. La segregación urbana es uno de los aspectos más preocupantes de la dinámica reciente de las ciudades latinoamericanas, que da cuenta de esta dolorosa separación - social y física - entre ricos y pobres, así como de enormes desigualdades en materia de viviendas, servicios urbanos, infraestructura y oportunidades de 
empleo entre los barrios que ocupan unos y otros. Los pobres realizan esfuerzos importantes para asentarse en la ciudad o para evitar ser desalojados de ella. Sus principales movilizaciones surgen ante la amenaza de una expulsión desde localizaciones centrales o cercanas a servicios y empleos. Ellos desean pertenecer a la ciudad, pero desde una perspectiva que difiere de la que sustentan las políticas urbanas que buscan atenuar la segregación. Estas últimas apuntan en general a que los pobres se asimilen a la ciudad convencional reemplazando sus asentamientos informales por conjuntos habitacionales convencionales de factura similar a los que existen en la ciudad formal y facilitando su acceso a los bienes y servicios que ésta ofrece. Por el contrario, las comunidades no necesariamente desean ser absorbidas por la ciudad "moderna" de los más acomodados, cuya referencia es la ciudad del mundo desarrollado. En América Latina, y con mayor razón en otros continentes en que en las ciudades conviven numerosas etnias, religiones y culturas, ellas perciben que su asimilación a la ciudad de los ricos no sólo tiene escasas posibilidades de concreción sino además podría no resultar deseable porque descarta atributos singulares del hábitat popular que se han perdido en el resto de la ciudad.

Las organizaciones populares tienen conciencia de las agudas carencias que afectan negativamente su calidad de vida y demandan que esta situación se corrija lo antes posible. Pero su visión de pertenencia a la ciudad tiene que ver más con la construcción de articulaciones y puentes entre ellas y otros grupos de ciudadanos, en que se reconozcan especificidades y se eliminen discriminaciones y desconfianzas. El avance hacia una ciudad más equitativa debería suceder con respeto a su identidad, diversidad y particular estilo de vida y convivencia.

\section{Cautela ante las políticas convencionales de vivienda}

La experiencia parece haber enseñado a los más pobres que sus problemas de vivienda no los van a resolver políticas públicas que focalizan la mayor parte de sus esfuerzos y recursos en la producción de nuevas viviendas. Conocen bien y sufren sus resultados, hasta ahora de escaso impacto sobre la precariedad del hábitat.

Aunque la mayoría de los países cuenta con entidades públicas especializadas para asumir técnica y políticamente la responsabilidad de proveer viviendas de interés social, en la práctica su tarea se ha visto limitada por aproximaciones demasiado rígidas y presupuestos insuficientes. La reducida proporción que representa el gasto público en vivienda dentro del gasto público social de la mayoría de los países ${ }^{3}$ y sus fluctuaciones en el tiempo dan cuenta de que este sector ha sido considerado como "prescindible" para los gobiernos cuando han aparecido otras prioridades presupuestarias. Si se considera además que los programas habitacionales privilegian la entrega de cantidades reducidas de viviendas de mayor calidad antes que atender con soluciones realistas a una mayor proporción de necesitados, se explica la cobertura restringida que no es consecuente con las enormes cifras de déficit acumulado: a comienzos de esta década unos cuarenta millones de hogares urbanos de los tres continentes no contaban con vivienda alguna, por lo que habitaban a la intemperie o "invadiendo" la privacidad doméstica de otras familias. Esta cifra de déficit cuantitativo aumenta al doble o al triple si se considera además el necesario reemplazo de viviendas destruidas por desastres y conflictos, la

\footnotetext{
${ }^{3}$ El gasto público en vivienda representa en 21 países latinoamericanos sólo un $1,2 \%$ del Producto Interno Bruto en comparación con el 4,3\% en educación, el 3,4\% en salud y el $7 \%$ en seguridad y asistencia social. Más aún, se observa una tendencia a disminuir su importancia desde los años de 1990 pese a que ha existido un aumento generalizado del gasto social total que benefició a los demás sectores sociales.
} 
provisión para familias desplazadas y la formación de nuevos hogares en las ciudades. Los pobres preferirían que las políticas de vivienda enfrentaran este gigantesco desafío de dotar de

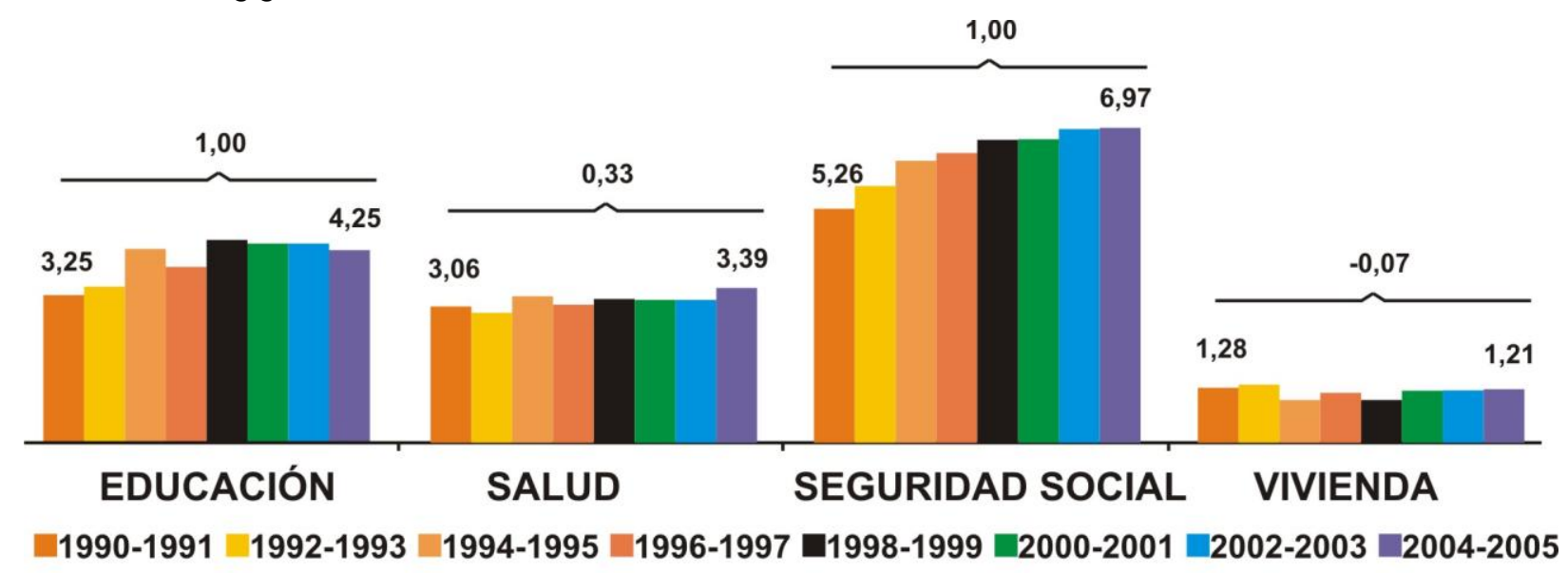

techo a tantos hogares sin casa adoptando estándares razonables y construyendo "menos para más" y así acortar los tiempos de espera y sufrimiento.

Figura 2. Gasto público social según sectores en Latinoamérica y El Caribe (\% del PIB-21 países). Fuente: Social Panorama of Latin America and the Caribean, 2007; ECLAL-UN.

En aquellos países latinoamericanos en que las políticas de vivienda lograron una cierta consolidación en el tiempo y redujeron gradualmente las carencias de vivienda, ha sido un problema constante evitar que segmentos de población menos pobres se beneficien de los recursos públicos destinados a proveer viviendas a los más necesitados. Se ha intentado mejorar la focalización reemplazando modelos que subvencionaban a la producción de viviendas sociales (ya sea absorbiendo parte del costo de construcción u otorgando franquicias tributarias a los oferentes) por otros que otorgan un subsidio estatal directo a la demanda. Estos cambios han traído beneficios, pero

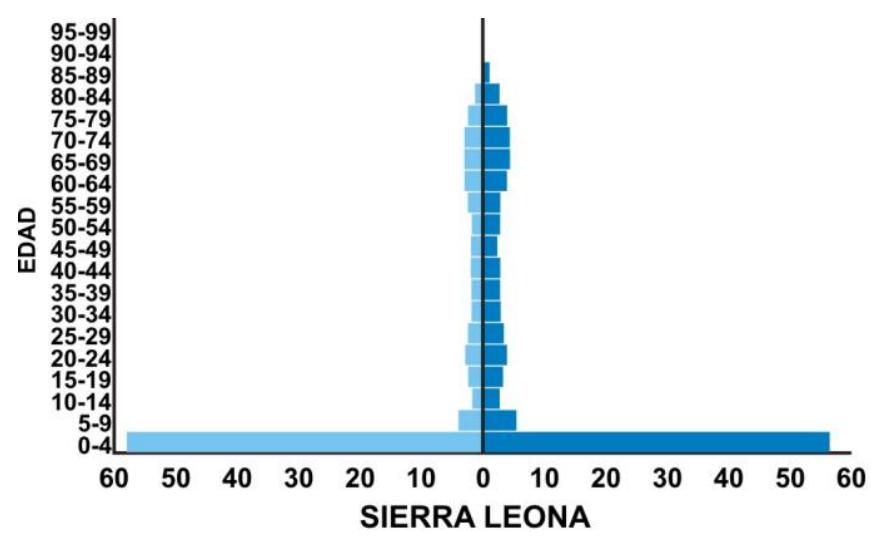


Para los hogares pobres el tiempo de espera es relevante ya que su vida puede ser más corta y riesgosa que para los segmentos más acomoda$\operatorname{dos}^{4}$ y las necesidades de cobijo apremian día a día. Sin embargo, el supuesto de que si ellos adquieren en el mercado habitacional "profesional" una vivienda terminada se garantizaría una mayor calidad los hace depender de políticas que, dados los reducidos presupuestos disponibles, implican esperar muchos años e incluso ver frustrado para siempre su anhelo de conseguir una vivienda.

\section{Los tugurios ¿problema o solución?}

En la medida que no encuentran respuestas realistas a sus necesidades, los pobres urbanos se asientan donde y como pueden, de forma ilegal, precaria, en terrenos de riesgo o en condiciones de hacinamiento. Con todo, los tugurios no son para ellos un problema sino un camino para acceder a la tierra y la vivienda en contextos donde no es posible hacerlo de otra forma.

Las autoridades reaccionan con diferentes actitudes ante la infatigable resolución de los pobladores por construir sus asentamientos. A veces ignoran la existencia de los tugurios, en otras ocasiones la toleran como "un mal menor" y a menudo emprenden acciones de desalojo que pueden llegar a altos grados de violencia y crueldad. Son menos frecuentes los programas que buscan radicar, regularizar y mejorar los asentamientos precarios, y en general ellos no resultan suficientes para hacer frente a la informalidad que presentan algunas ciudades. Por eso algunos profesionales que trabajan junto a los pobres urbanos sostienen que en el mediano plazo sólo los tugurios podrán proveer suficientes viviendas a los pobres, y que dadas las condiciones políticas y urbanísticas que prevalecen en el mundo en desarrollo, lo que se necesitaría hoy son más

\footnotetext{
${ }^{4}$ Para un niño en Sierra Leona, África, morir antes de los 5 años es una probabilidad alta, mientras un niño del mundo desarrollado posiblemente superará los 78 años.
}

tugurios, pero tugurios con potencial para dejar atrás la precariedad dentro de los próximos quince o veinte años ${ }^{5}$.

Si las políticas habitacionales aceptaran el reto de colaborar para lograr el progreso gradual de los tugurios en vez de soñar con borrarlos de la ciudad, deberían ampliar sustancialmente la escala de las iniciativas que ya existen para combatir la precariedad. Necesitarían además adquirir capacidades para ejecutar intervenciones de mayor complejidad y diversidad que la producción en serie de viviendas sociales, así como articular iniciativas entre diferentes áreas, niveles y sectores. Pero el mayor desafío será sin duda aceptar que en estos programas los propios habitantes no pueden continuar siendo considerados como meros beneficiarios sino como actores relevantes con voz y voto respecto de las prioridades y acciones que se ejecutarán.

En el contexto latinoamericano es necesaria además una precisión respecto del tema de los tugurios. A diferencia de lo que sucede en el resto del mundo en desarrollo, acá la asimilación entre tugurio y precariedad se ha desdibujado debido a que no todos los habitantes de tugurios viven en la precariedad, ni tampoco se concentra la precariedad necesariamente en barrios informales. Por un lado, conjuntos de vivienda social de bajo estándar construidos en el pasado por programas públicos se han deteriorado hasta convertirse en focos de precariedad. Por otra parte, antiguos tugurios han logrado progresar junto con la ciudad y hoy ya no reflejan su origen precario. En muchas ciudades la precariedad no se encuentra concentrada en tugurios sino dispersa en el tejido

\footnotetext{
5 Mayor información sobre este enfoque de los tugurios se encuentra en: ARIF, Hasan. Why do we need more slums in Asia, Asian Coalition for Housing Rights, 2003. Accesible en: $<$ www.achr.net/arif_hasn1.htm>. (Consultado el 29 de agosto de 2012). Una versión traducida y comentada de dicho texto se puede consultar en el recuadro 4, página 12 de la ponencia "Pobres en ciudades pobres: una mirada desde América Latina", (Mac Donald, 2006). $<$ www.reduniversitaria.es/ficheros/JoanMacDonald.pdf>. (Consultado el 29 de agosto de 2012).
} 
urbano. Las familias latinoamericanas pobres han consolidado su vivienda paso a paso con pequeñas mejoras, de modo que a comienzos de la década un $26 \%$ de ellas no tenía carencias en su alojamiento y sólo un $10 \%$ habitaba en precariedad extrema ${ }^{6}$. Para nuestra región los programas que ayuden a los pobres a mejorar su nivel habitacional no sólo deberían concentrarse entonces en los tugurios sino abarcar una amplia gama de situaciones urbanas precarias presentes en diferentes barrios de la ciudad.

\section{Productos y procesos}

Circunstancias como el origen histórico del sector vivienda, el tipo de profesionales que lo integran y los intereses implícitos en el negocio de la construcción han instalado en las políticas habitacionales una mirada predominante sobre el "producto" vivienda. La preocupación respecto del "proceso" de alojamiento, que adquiere gran importancia en las estrategias que aplican las familias pobres y sus organizaciones, sigue siendo un componente menor para las entidades públicas. El enfoque centrado en resultados ha logrado en muchos casos resolver necesidades concretas, pero no ha generado procesos que den poder y autonomía a las comunidades para asegurar un desarrollo sostenible del hábitat popular.

Los programas de vivienda impulsados desde otras entidades de la sociedad civil -a menudo con el apoyo de la cooperación internacional- dan mayor importancia a estos procesos, pero no han logrado escalas significativas como para constituirse en alternativas reales a los programas públicos convencionales. A su vez, diversas organizaciones internacionales y nacionales promueven movimientos y campañas en el marco de los derechos económicos, sociales y culturales, para luchar por asuntos como el acceso a una vivienda

${ }^{6}$ Estas cifras corresponden a promedios ponderados de 14 países de la Región. Para mayores antecedentes consultar Mac Donald \& Mazzei (2004). digna, la cesación de erradicaciones o el derecho a la ciudad. Han conseguido instalar estos temas en la opinión pública y las bases legales y constitucionales de muchos países, pero hasta ahora los resultados prácticos para los pobres urbanos han sido discretos. La experiencia parece señalar que las iniciativas exclusivamente orientadas a procesos pueden lograr efectos movilizadores por algún tiempo, pero si no conducen a logros palpables para los habitantes estos procesos se debilitan y mueren.

¿Deberían las políticas de vivienda necesariamente optar entre la entrega de productos concretos y la promoción de procesos para aumentar su efectividad? Para las familias y los grupos que sufren día a día apremiantes necesidades de alojamiento la distinción entre una aproximación desde el producto y otra desde el proceso no tiene demasiada importancia. A la hora de resolver la precariedad o la falta de viviendas las oportunidades existentes determinan la conveniencia de arrancar desde el producto o el proceso. A veces las iniciativas focalizan de manera muy concreta en la obtención de una casa, un lote o un servicio, pero para lograrlo se requiere organización, acumulación de recursos o capacitación, procesos que anteceden a la demanda específica y perduran más allá del logro de ésta. A su vez, cuando se integran movimientos para luchar contra un desalojo inminente o para lograr un techo, se espera obtener mejoras muy concretas al cabo de este proceso. Esta práctica de combinar productos y procesos es un aporte significativo de los pobres urbanos a las políticas habitacionales. Ya sea que se arranque de la lucha por "productos" concretos o de la promoción de procesos más amplios, lo importante es que en el primer caso sea posible fortalecer actitudes y actividades proactivas que perduren en el tiempo y en el otro caso los procesos logren solucionar efectivamente los problemas que les dieron origen. 


\section{Un ejemplo de producto exitoso}

En el trabajo en terreno también aprendemos a

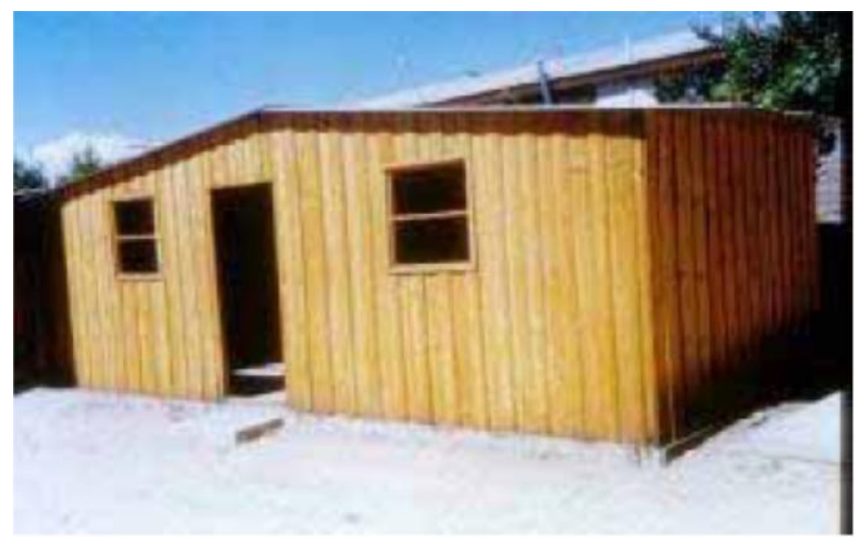

Una experiencia chilena que ha resultado exitosa en este campo ha sido el programa de "mediaguas" desarrollado en Chile por el Hogar de Cristo desde fines de la década de $1950^{7}$. Entre los rasgos que explican su efectividad está el reconocimiento explícito de que se está abordando un problema tan masivo y urgente que no cabe sino aceptar que "más vale una mala casa ahora que una vivienda mejor en diez años más"8. Por eso se ha optado por un alojamiento mínimo cuyo costo hoy se sitúa en unos US $\$ 450$. La industrialización y la producción masiva de componentes permiten además lograr volúmenes importantes de producción que pueden alcanzar hasta trescientas unidades diarias en situaciones de extrema emergencia social.

Otra característica del programa es que no sustituye sino reconoce y aprovecha las capacidades de las familias para llevar adelante su proceso habitacional. Provee sólo aquello que ellas no pueden aportar dados sus escasos ingresos -los

\footnotetext{
7 Este programa de la Fundación de Vivienda Hogar de Cristo entrega desde el año 1958 a familias de extrema pobreza los componentes para que ellos construyan un albergue ("mediagua"). Según sea el tamaño de la familia, se provee cuatro paneles de madera (una vivienda de $3 \times 3 \mathrm{~m}^{2}$ ) o seis paneles (para construir una vivienda de $3 \times 6 \mathrm{~m}^{2}$ ), además de planchas de techo, una puerta y una ventana. Hasta la fecha se han entregado unas 450.000 unidades que representan 7,9 millones de $\mathrm{m}^{2}$.

${ }^{8}$ Esta afirmación es sostenida con vehemencia por el $P$. Josse van der Rest s.j, fundador de SELAVIP y Capellán de la Fundación de Viviendas Hogar de Cristo.
}

reconocer algunos atributos que debería tener un producto habitacional para promover el desarrollo en este sentido de los más pobres de los pobres.

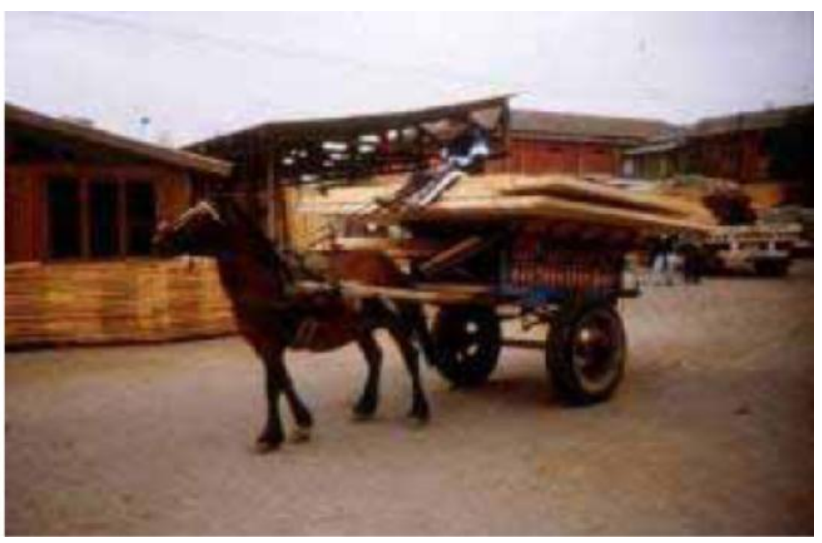

componentes "duros" -y responsabiliza a los propios hogares de las demás tareas como conseguir un terreno -propio, invadido o cedido- preparar la instalación y armar la vivienda. El paquete de paneles y materiales anexos que se entrega en fábrica es relativamente liviano (entre $400 \mathrm{y}$ $600 \mathrm{Kg}$.) para que el traslado lo pueda efectuar la familia con sus propios medios de transporte. El montaje se completa en pocas horas con la ayuda de algún vecino o pariente. La mediagua, simple, fácil de armar por las propias familias, evita que ellas dependan de instituciones, profesionales y procesos administrativos complejos.

Para colaborar efectiva y oportunamente con los más pobres de los pobres, este programa desliga la provisión de la vivienda de la condición de que la familia posea un lote. Una vivienda desarmable y movible como la mediagua permite resolver "mientras tanto" la necesidad de techo y empezar a luchar por la vivienda definitiva. En otros casos las familias han invadido un terreno y necesitan consolidar su permanencia en él. La mediagua, armada a veces sigilosamente durante la noche, les permite consolidar la ocupación y empezar a habitar el nuevo asentamiento.

Un programa de este tipo tiene detractores en los ámbitos más diversos. Una vivienda tan elemental no parece aceptable para los gobiernos, políticos, empresarios, académicos e instituciones sectoria- 
les. Tampoco se ajusta a los requisitos que plantean ordenanzas urbanísticas y constructivas importadas del mundo desarrollado. Exige operar fuera de los circuitos formales de construcción y saber enfrentar las críticas respecto de la aceptabilidad "ética" de la mediagua". Sin embargo, estos modestos albergues cumplieron un rol importante en Chile cuando un déficit agudo obligaba a miles de familias a una coexistencia forzada, en grados de hacinamiento y promiscuidad que ponían en peligro la supervivencia de los lazos familiares. El concepto de "vivienda posible" opuesto al de una "vivienda digna" de concreción tardía e incierta resulta difícil de aceptar por los que ya tienen una buena vivienda, pero es comprendido por los que viven en condiciones de extrema precariedad. Por eso encuentra cada vez más aceptación entre los pobres de muchos países de Asia, África y América Latina, donde se busca cumplir con atributos como los señalados con tecnologías y diseños propios.

La experiencia arriba descrita parece comprobar que nada impediría poner al alcance de los pobres alojamientos mínimos a costos razonables y escalas acordes con las necesidades acumuladas. Sin embargo, es necesario reconocer que el principal obstáculo que enfrentan en su proceso habitacional no es la falta de vivienda sino su exclusión del suelo urbano. Cabe destacar por ello el esfuerzo que algunas políticas habitacionales han efectuado en el pasado por otorgar a los más pobres un terreno - a veces urbanizado y en ocasiones simplemente trazado- para anticipar de manera realista la formación espontánea de

\footnotetext{
${ }^{9}$ La propia precariedad de la mediagua ayuda a que ella sea tolerada por la autoridad y los expertos, ya que no es considerada siquiera como una solución mínima. De este modo no libera al gobierno de la responsabilidad de otorgar una vivienda digna, sino por el contrario, lo incentiva a hacerlo. Mientras tanto, para los pobres urbanos se trata de un primer paso en un proceso que se completará en muchos años más.
}

$\operatorname{asentamientos}^{10}$. Aunque se reconoce que en barrios de generación informal la posterior instalación de servicios y regularización legal puede resultar mucho más costosa y difícil que en un "tugurio planificado", los programas de acceso al suelo urbano a través de lotes y lotes urbanizados no encuentran acogida en los sectores vinculados al mercado del suelo y la construcción, que prefieren guardar sus tierras para negocios más rentables. Tampoco gustan a las entidades dedicadas a la vivienda social, que estiman que no sería "digno" entregar al pobre sólo un pedazo de tierra. Sin embargo, las propias familias comprenden que teniendo un pedazo de suelo con el tiempo llegarán a tener su casa y formarán parte de la ciudad. Por eso su primera prioridad siempre será conseguir un terreno o defender el que ya ocupan, aunque les resulte tan difícil superar las múltiples barreras que les impone el mercado del suelo urbano y los prejuicios de políticos y profesionales.

\section{La ventaja de ser muchos}

En las ciudades de Asia habita cerca de la mitad de la población urbana del planeta y la mayoría de los pobres urbanos y de los habitantes de tugurios. Paradójicamente, las enormes carencias acumuladas en los centros urbanos han sido el motor de respuestas innovadoras a los problemas de los pobres urbanos. Los grandes volúmenes de carencias pueden ser un problema para los gobiernos, pero en algunos países los pobres los han convertido en potencial de solución. En vez de luchar aisladamente por resolver sus problemas se han organizado y federado en entidades nacionales e internacionales de alta representatividad y capacidad de presión. Han aprovechado este poder para asociarse ventajosamente con los gobiernos de las ciudades y así influir en el

\footnotetext{
10 Estadísticas de los años de 1970 señalan, por ejemplo, que en Chile se otorgaron cerca de 180.000 lotes en la llamada "Operación Sitio".
} 
desarrollo urbano, atenuar las erradicaciones y consolidar los tugurios. A su vez los municipios y gobiernos entienden las ventajas de trabajar con estas organizaciones para ejecutar intervenciones de gran escala y reducir costos a través de métodos participativos. Una gran lección que ofrece la experiencia asiática en este campo es que resulta posible para los pobres urbanos ser actores eficientes en los procesos urbanos, si utilizan la escala masiva de sus organizaciones no sólo para reivindicar sus derechos sino también para acumular recursos e ideas para resolver sus problemas.

La experiencia de estos movimientos podría ser útil para América Latina, donde las organizaciones populares tienden a una dispersión que debilita sus posibilidades de influir en la dinámica urbana. A su vez, muchas organizaciones prefieren identificarse con la confrontación y la denuncia y muestran menos disposición a acumular recursos o participar en programas públicos y privados que sus pares en otros continentes. Las políticas del hábitat regionales por otra parte son indiferentes e incluso desconfiadas respecto de la posibilidad de trabajar con las organizaciones para evitar la confrontación o las complicaciones que conlleva una gestión participativa. Si los movimientos populares asiáticos lograron a través de una actitud más abierta al trabajo asociativo avances importantes en asuntos como la tenencia del suelo, la radicación de asentamientos, los estándares de vivienda y el acceso a servicios, también es posible visualizar acá beneficios similares a partir de una interlocución constructiva entre las organizaciones y el ámbito político institucional.

\section{Estrategias urbanas articuladoras}

Para una familia pobre, una localización que facilite el acceso a bienes y servicios urbanos resulta tan importante que está dispuesta a transar seguridad, salubridad y calidad habitacional por obte- ner o mantener una buena accesibilidad. Pero la dinámica urbana pone en peligro su permanencia en asentamientos informales bien ubicados, sobre todo si los terrenos adquieren valor urbanístico o comercial. Las expulsiones -masivas y dispersas- originadas en la presión del negocio inmobiliario, la normativa de "desarrollo urbano" o las propias políticas de vivienda son una amenaza constante. Ya mencionamos que los pobres ya saben que las estrategias de denuncia y confrontación -incluso aquellas apoyadas o implementadas por entidades internacionales y nacionalespueden haber llevado a las autoridades a tomar conciencia oportuna respecto de estas situaciones, pero no han logrado en la mayoría de los casos evitar que se concreten las expulsiones.

Por eso se intentan ahora otros caminos para manejar las amenazas de desalojo y enfrentar a los poderosos intereses que subyacen a ellas. Además de la hábil utilización de la gran escala que ya mencionamos anteriormente, se establecen escenarios "gana-gana" en que no sólo los pobladores amenazados sino las otras partes involucradas -vecinos, municipios, sector privado, etc.- también puedan lograr beneficios. Estas estrategias impulsadas por las propias comunidades no buscan tanto "quebrar la mano" de la autoridad sino lograr que se atienda a la mayor parte de sus objetivos centrales, para lo cual están dispuestas a ciertas concesiones. Por ejemplo, se entrega parte del terreno ocupado para fines comerciales o urbanos, lo que implica reasentamientos, densificación y reducción de los espacios de la vivienda. En otros casos se acuerdan períodos de ocupación que dan a las familias una cierta seguridad en el mediano plazo y aseguran a los dueños legales de los terrenos habitados que los recuperarán más adelante. Esta actitud realista de las organizaciones se basa en su constatación de que en un enfrentamiento radical con las autoridades o el sector privado, ellas tie- 
nen más posibilidades de perder que si buscan articular intereses. El aprendizaje entre comunidades a nivel vecinal, nacional, regional e incluso internacional sobre estrategias articuladoras ha sido fundamental para elaborar y refinar estos novedosos procedimientos.

\section{Manejar la información, dibujarse en los mapas}

Los sectores populares saben que los gobiernos con frecuencia recurren a la desinformación para evadir sus responsabilidades para con los pobres y los tugurios. No registran a los primeros como ciudadanos "convencionales" ni incluyen a los segundos en los mapas de las ciudades. Ante esto, acumular información acerca de su situación ha pasado a ser fundamental en la lucha de los grupos por el mejoramiento de su hábitat. "Colocarse en el mapa" y documentar lo que sucede en el tugurio permite dar a conocer su existencia, pero también constituye un "ritual"11 para conocer, dimensionar y documentar sus propios problemas, identificar recursos para superarlos y adquirir destrezas para exponerlos ante la sociedad. Desde la precisión del número de familias que integran el tugurio, la confección de un bosquejo o mapa de la conformación física del asentamiento y las viviendas, la colocación de números domiciliarios provisorios en las viviendas se avanza de manera participativa hacia propuestas consensuadas como base para la negociación con las autoridades. El conocimiento vivencial de la realidad y los problemas, las habilidades sobre todo de las mujeres para recolectar datos precisos sobre cada hogar o vivienda y el acceso a tecnologías modernas para procesar esta información ha permitido a los pobres urbanos recuperar el

\footnotetext{
11 Habitantes de tugurios de Asia y África se han organizado en comunidades y federaciones nacionales e internacionales para constituir una entidad Ilamada "SDI - Slum Dwellers International". SDI ha desarrollado nueve "rituales" o prácticas que aplican sus integrantes en los diversos países. Más referencias acerca de SDI y los detalles de estos "rituales" en su web, <www.sdinet.org $>$.
}

acceso a información que hasta hoy guardaban celosamente los expertos e instituciones. El activo intercambio de conocimientos y experiencias entre comunidades en este área ha ido convirtiendo a los pobres urbanos en interlocutores válidos, capaces de plantear sus problemas y negociar soluciones efectivas.

\section{Potenciar capacidad financiera y tecnológica}

En nuestra región se ha extendido la afirmación de que los más pobres no pueden ahorrar para su vivienda, y que resulta inaceptable que lo hagan si se los quiere sacar de la pobreza. Sin embargo, en otras regiones aún en las situaciones de mayor precariedad los pobres urbanos hacen importantes esfuerzos de ahorro para mejorar su vivienda o asentamiento. La sorprendente capacidad de acumulación de recursos financieros de las familias cuando se organizan en torno a un fin común ha generado en Asia y África esquemas de ahorro popular incluso entre los grupos de mayor pobreza y vulnerabilidad, como por ejemplo los habitantes de la calle. Las comunidades pobres hoy reconocen que en un mundo en que deciden aquellos que tienen más recursos ellos no tendrán poder de decisión si no poseen algún ahorro. Los procesos de ahorro y crédito grupal controlados por las propias comunidades se basan en sucesivos aportes de pequeños montos por parte de grandes cantidades de familias pobres. De esta forma se han llegado a acumular cantidades importantes de recursos que permiten abordar los problemas con mayor prestancia que si se dependiera exclusivamente de la voluntad de autoridades públicas o de financiamientos externos. Nuevamente, esta práctica no sólo ha logrado beneficios financieros, sino además promueve en la comunidad actitudes responsables, solidarias y realistas para mejorar la calidad de vida. Se aprende a tomar riesgos y se refuerza la confianza en las propias capacidades del grupo. 
A la luz de los sorprendentes resultados obtenidos y la viabilidad comprobada de establecer sistemas de ahorro aún en comunidades extremadamente pobres se podrían revisar conceptos que subyacen a muchos programas en nuestra región, que tienden a subvalorar las capacidades de los pobres urbanos para aportar a su desarrollo.

Algo similar sucede en el campo tecnológico. En América Latina existió en el pasado una gran capacidad del sector popular para autogestionar su hábitat. Muchas ciudades le deben a esta capacidad la mayor parte de su tejido urbano y capital constructivo. Sin embargo, las tendencias de las políticas habitacionales y los poderosos intereses del sector inmobiliario han deteriorado esta capacidad tecnológica hasta casi anular su existencia. No sucede lo mismo en otras regiones en que las políticas de vivienda han sido más débiles o inexistentes, y el auto-alojamiento sigue siendo la manera predominante de acceder a la vivienda por parte de los pobres. Por ejemplo, en países de África encontramos experiencias muy positivas de producción de hábitat por parte de las familias con mejores resultados en materia de costo y calidad que la producción de empresas comercia$\operatorname{les}^{12}$. Una "ventaja del retraso" del sector habitacional en estos países podría ser que aún es posible diseñar políticas de vivienda que preserven la capacidad tecnológica de los habitantes y no la erosionen como sucedió en nuestro continente.

Fortalecer la capacidad técnica de las familias pobres no sólo ha sido beneficioso para ejecutar programas habitacionales de consolidación progresiva y de autoconstrucción. Incluso en países en que esta modalidad no tiene gran relevancia,

\footnotetext{
12 Las estrategias de autogestión del hábitat han tenido además interesantes efectos en materia de equidad de género. Por una parte han mantenido un rol claro e importante para los hombres en procesos habitacionales principalmente liderados por mujeres, evitando una desvinculación que no ha probado ser positiva. En otros casos han provisto a las mujeres de capacidades en materia de construcción y administración de obras, aumentando el potencial de recursos técnicos del asentamiento y generando interesantes oportunidades de ingresos para ellas.
}

poseer conocimientos técnicos básicos sobre el producto que se entrega a las familias las convierte en "clientes informados" que no aceptarán a ciegas lo que les ofrece el Estado o el sector privado. Cuando los bienes y servicios habitacionales se proveen desde fuera -como sucede por lo general en ambientes de subsidio- las familias requieren conocer de diseño y construcción para evaluar su futura vivienda. La exhibición de modelos a escala real que familiarizan a las comunidades con las dimensiones reales de sus futuras casas, las visitas a otros conjuntos ya habitados y los intercambios entre comunidades para discutir ventajas y desventajas de diseños y sistemas constructivos son prácticas que ayudan a equilibrar el poder de la demanda con el de la oferta, en un mercado habitacional en que el "cliente" es especialmente débil para imponer preferencias o demandar calidad a los que construyen y financian su vivienda.

\section{Comentario final}

En medio del acelerado proceso de urbanización que somete a las ciudades a permanentes desafíos, surgen desde las comunidades pobres experiencias a veces exitosas y en muchos casos dolorosas que sugieren nuevas ideas y prácticas en el campo de la consolidación de los asentamientos informales y de los centros urbanos en su conjunto. Hemos planteado diez temas que podrían ser especialmente interesantes de analizar desde esta perspectiva. Comparamos conceptos que subyacen a nuestra manera de entender la pobreza, la precariedad y la segregación urbanas con aquellos que están detrás de las formas en que los pobres localizan y construyen su hábitat. Analizamos luego algunos rasgos de las políticas convencionales de vivienda que podrían explicar los resultados discretos que están logrando para solucionar el problema de los sin techo. Al estar centradas en la producción de casas, estas políti- 
cas no valoran ni refuerzan de manera suficiente los procesos implícitos en la creación de asentamientos y viviendas como lo hacen los propios habitantes de tugurios. Identificamos además algunos atributos que debería tener la provisión de viviendas para resolver realmente el problema de albergue de los más pobres entre los pobres. Finalmente se identifican algunos recursos estratégicos que los movimientos populares están aprendiendo a usar para fortalecer los procesos de mejoramiento del hábitat precario, como el empleo de la gran escala, la articulación de intereses, las ventajas de una información oportuna y el desarrollo de capacidades en materia financiera y tecnológica.

Estas estrategias merecen ser consideradas con atención por aquellos que estudian los problemas urbanos y habitacionales y las entidades que formulan e implementan políticas es este área, ya que dan cuenta de una creatividad que a veces no encontramos en las aproximaciones convencionales. Es necesaria en primer lugar una disposición real para revisar algunos preconceptos, objetivos y prioridades fuertemente arraigados en el sector y reconocer que los habitantes de los asentamientos precarios no pueden seguir siendo considerados como meros objetos de las políticas urbanas y habitacionales. En experiencias exitosas, observadas sobre todo en Asia y África, ellos son protagonistas o valiosos interlocutores que aportan ideas, recursos y operatividad a los pro$\operatorname{gramas}^{13}$.

\footnotetext{
13 Esta constatación es válida no sólo en relación a las esferas de gobierno. Casi todos los procesos habitacionales exitosos cuentan con un firme respaldo profesional y técnico de parte de organizaciones no gubernamentales, académicas o de otro orden. Pero la relación entre éstas y las comunidades es diferente a lo que con frecuencia sucede en esta región. En nuestro caso las entidades técnicas por lo general asumen la representación de las bases ante autoridades y proveedores de recursos externos. Actúan como la "cabeza visible" de los proyectos mientras los pobres urbanos quedan relegados al rol de "clientes" o beneficiarios. Por el contrario, en los procesos realmente liderados por las comunidades los representantes de éstas son los interlocutores y responsables de las decisiones y recurren a los técnicos para los asuntos y en los momentos que estiman necesario.
}

Las tres regiones en desarrollo enfrentan diferentes desafíos para incorporar estos aportes a las políticas. En un extremo, sólo unos pocos países africanos cuentan con políticas asentadas en materia de vivienda, de modo que allí las tareas son introducir estrategias lideradas por las comunidades en los nuevos programas y estar atentos a que la introducción de políticas "modernas" desde otras regiones no ponga en peligro la permanencia de un bagaje valioso de destrezas que los pobres están aplicando para mejorar su hábitat. En el otro extremo, América Latina es una región de larga y amplia tradición en materia de programas públicos de vivienda social. Sin embargo, acá los organismos sectoriales parecen renuentes ante la posibilidad de entregar espacios de decisión a los pobres urbanos. Se requiere en este caso re-establecer confianzas y respetos mutuos que se han perdido durante décadas de "modernización" de las políticas en que en aras de la eficiencia se marginó a las comunidades pobres de la gestión del hábitat. A su vez, las propias organizaciones populares latinoamericanas tienen por delante tareas importantes si quieren retomar un rol protagónico en la construcción de ciudades. Prácticas como las que hemos descrito, que han desarrollado sus pares en otras regiones, pueden resultar útiles para conseguirlo. Finalmente, los países asiáticos tienen enormes diferencias entre sí, con realidades particulares que los sitúan en puntos diferentes en materia de trayectoria habitacional. La contribución muy especial de los pobres urbanos en este continente es que ellos destacan el potencial que implican la escala masiva y las asociaciones constructivas como ingredientes básicos de una política participativa en materia de asentamientos humanos, asimismo están logrando emplear este potencial a su favor con gran efectividad. 


\section{Referencias}

ARIF, Hasan. Why do we need more slums in Asia?, Asian Coalition for Housing Rights, 2003. $<$ www.achr.net/arif_hasn1.htm>. (Consultado el 29 de agosto de 2012).

MAC DONALD, Joan. Pobres en ciudades pobres: una mirada desde América Latina, In Pobres en ciudades pobres. Vivienda, transporte $y$ planificación urbana. Ponencias del I Congreso Internacional sobre Desarrollo Humano, Madrid: Cooperación Ciudad de Madrid, 2006. $<$ www.reduniversitaria.es/ficheros/JoanMacDon ald.pdf>. (Consultado el 29 de agosto de 2012). MAC DONALD, Joan y MAZZEI, Marinella. Pobreza y precariedad del hábitat en las ciudades de América Latina. Santiago de Chile: División de Desarrollo Sostenible y Asentamientos Humanos, Comisión Económica y Social para América Latina y El Caribe (CEPAL), Naciones Unidas, Serie Manuales, № 38, 2004. <http://www.eclac.cl/publicaciones/xml/0/20640/l cl2214e.pdf>. (Consultado el 29 de agosto de 2012).

\section{Cita del artículo}

MAC DONALD, J. CIUDAD, POBREZA, TUGURIO.

Aportes de los pobres a la construcción del hábitat popular. Hábitat y Sociedad, 2011, № 3, p. 13-26.

$<$ www.habitatysociedad.us.es $>$.

http://dx.doi.org/10.12795/HabitatySociedad.2011.i3.02 